\title{
Introducing the nutrition \& metabolism section of journal of translational medicine
}

\author{
Laura Soldati, Elena Dogliotti, Irene Camera and Annalisa Terranegra
}

\section{Our food should be our medicine. Our medicine should be our food. Hippocrates (460 BC - 377 BC)}

Nutrition experts, as well as specialists of different pathologies, are disclosing an ever increasing interest for protocols devoted to the welfare of patients and to prevention of nutrition related diseases.

In fact, it is extensively acknowledged that nutrition plays a primary role in those complex diseases most widespread in the western countries like cardiovascular disease [1], cancer [2], Alzheimer's disease [3], diabetes [4], nephrolithiasis [5] etc. that account for over $60 \%$ of deaths world-wide.

Even in our country, Italy, and in other South Europe's countries, until now protected by the Mediterranean diet, which in 2010 was awarded by UNESCO the human heritage status, the next generation will be the first with a life expectancy lower than of their parents, principally due to unhealthy eating habits and the obesity epidemic.

To counteract this trend, in the last decade attention has been focused on the human nutrition field, with significant research topics being new molecules contrasting cholesterol accumulation in the arterial walls or capable of diminishing visceral fat [6], the role of bacterial microflora [7], the production of functional foods, studies on antioxidant properties of vitamins and polyphenols, etc.

Moreover, beside knowledge acquired with traditional investigation techniques, the field of human nutrition can now avail itself of the new omics techniques that could give a significant contribute to mapping the interactions between genetics, nutrition and health [8].

In the area of Translational Medicine, we believe that the field of nutrition ought to be taken into greater account, as an interaction and mutual validation agency between basic and applied research, in order to generate advanced applications for diagnosis and therapy and to

\footnotetext{
* Correspondence: laura.soldati@unimi.it

Department of Medicine, Surgery and Dentistry, Università degli Studi di Milano, Milan, Italy
}

(C) 2012 Soldati et al; licensee BioMed Central Ltd. This is an Open Access article distributed under the terms of the Creative Commons

develop at the same time new instruments of investigation.

We here propose a new section devoted to the rapid publication of research papers on all aspects of nutrition with applications in medicine and biotechnology.

This section welcomes contributions that employ traditional clinical, metabolic and epidemiologic methods, but is also open to molecular and cell biology research applied to animal and human nutrition.

Topics include: diet interactions in chronic diseases, gene-environment interactions, genes and cell metabolism, protein and aminoacid metabolism, lipid metabolism and diseases, carbohydrate metabolism and diseases, micronutrients and functional foods.

Other topics relevant to nutrition will be appreciated as well.

Received: 9 January 2012 Accepted: 30 January 2012

Published: 30 January 2012

References

1. Bhupathiraju SN, Tucker KL: Coronary heart disease prevention: nutrients, foods, and dietary patterns. Clin Chim Acta 2011, 412:1493-1514.

2. Ross SA: Evidence for the relationship between diet and cancer. Exp Oncol 2010, 32:137-142.

3. Ramesh BN, Rao TS, Prakasam A, Sambamurti K, Rao KS: Neuronutrition and Alzheimer's disease. J Alzheimers Dis 2010, 19:1123-1139.

4. Mangou A, Grammatikopoulou MG, Mirkopolou D, Sailer N, Kotzamanidis C, Tsigga M: Associations between diet quality, health status and diabetic complications in patients with type 2 diabetes and comorbid obesity. Endocrinol Nutr 2011, Epub ahead of print.

5. Meschi T, Schianchi T, Ridolo E, Adorni G, Allegri F, Guerra A, Novarini A, Borghi L: Body weight, diet and water intake in preventing stone disease. Urol Int 2004, 72(suppl 1):29-33.

6. Last AR, Ference JD, Falleroni J: Pharmacologic treatment of hyperlipidemia. Am Fam Physician 2011, 84:551-558.

7. Scarpellini E, Campanale M, Leone D, Purchiaroni F, Vitale G, Lauritano EC, Gasbarrini A: Gut microbiota and obesity. Intern Emerg Med 2010, 5(suppl 1):S53-56

8. Kussmann M, Affolter M: Proteomics at the center of nutrigenomics: comprehensive molecular understanding of dietary health effects. Nutrition 2009, 25:1085-1093.

doi:10.1186/1479-5876-10-17

Cite this article as: Soldati et al.: Introducing the nutrition \& metabolism section of journal of translational medicine. Journal of Translational Medicine 2012 10:17. 